\title{
Promoting homeownership at the margins: the experience of low-cost homeownership purchasers in regeneration areas
}

\author{
Kim McKee* \\ University of St Andrews
}

\begin{abstract}
An important element of Scottish housing policy in recent years has been the use of tenure-mix as a regeneration strategy. This has been achieved through Low-Cost Initiatives for First Time Buyers (LIFT), which includes schemes such as shared equity and shared ownership. Yet in-depth interviews with individuals who purchased properties through these schemes, suggests they pose a number of problems and challenges. In turn, this raises the important public policy question of whether it is appropriate for the Scottish Government to encourage low-income households to become homeowners in the first place.
\end{abstract}

Keywords: housing policy, low-cost homeownership, regeneration, Scotland, shared equity, shared ownership, tenure-mix.

\section{Introduction}

The growth of homeownership in the UK was one of the most significant social changes of the 20th century. It reflects the way in which owner-occupation has become a 'normalised' form of housing consumption, and promoted in policy and political discourses as the 'natural' and 'preferred' tenure of choice (Gurney, 1999). Although unevenly distributed it is the most widely held asset, and an important source of individual and national wealth (Stephens, et al, 2008). As such, government, at both the UK and devolved levels, have ambitions to expand it beyond its current rate of 70 per cent in England and 65 per cent in Scotland (CLG, 2007 and SG, 2007), a goal that is to be achieved through a plethora of low-cost homeownership products that seek to promote and facilitate homeownership amongst low and middle income groups, especially first-time buyers.

Housing is a devolved matter in the UK context, and policy initiatives designed to increase homeownership vary across the four jurisdictions. This paper focuses on the Scottish context where low-cost homeownership has occupied a pivotal role in delivering government policy objectives around regeneration and social inclusion (SG, 
p. 39. Promoting Homeownership at the Margins: the experience of low-cost homeownership purchasers in regeneration areas

2007). Historically, levels of homeownership in Scotland have been lower than the rest of the UK, with the size of the social rented sector also being larger. Research highlights that it is in those areas which have the greatest proportion of social housing that low-cost homeownership initiatives have delivered the greatest impact in terms of diversifying the tenure structure. Dorling and Thomas (2004) estimate that in 2003, 29 per cent of all owners in Scotland lived in a house that was previously owned by a public sector landlord (cited in Munro, 2007). Whilst the right to buy has without doubt been the most successful attempt at promoting low-cost homeownership in the UK, more recent policy initiatives have also made important contributions in delivering affordable housing for those on modest incomes, such as shared ownership and shared equity products. This paper draws on empirical data from an exploratory qualitative study which endeavoured to understand the views and experiences of households who purchased their property through shared equity/ownership schemes within a regeneration context. The focus on regeneration areas is important and deliberate, for low-cost homeownership schemes have traditionally been successful in high pressure housing areas such as Edinburgh and the Lothians, and in a UK context, England and the south-east. However, in a regeneration context these schemes have a different role to play, and are important policy vehicles in delivering government objectives around tenure-mix and social inclusion. The next section of the paper summarises the literature on tenure-mix and low-cost homeownership in the Scottish context. This is followed by some discussion of the research design, and then an exploration of the empirical data.

\section{Tenure-mix as a regeneration strategy in Scotland}

The creation of 'mixed communities' through tenure diversification has been pivotal to regenerating public housing estates in the UK under the New Labour administration (see for example, Tunstall, 2003; Mclntyre and McKee, In Press). It is a policy agenda that seeks to introduce more affluent homeowners into areas previously dominated by low-cost social renting, and in doing so increase social mix at the neighbourhood level. The political assumption underpinning much of this policy rhetoric is not only that mono-tenure public housing estates have 'failed', but that owner-occupation is the solution to solving the 'problem' of poor communities by 'reconnecting' them to mainstream society. It has been a particularly important element of regeneration strategies in Scotland, where a notable feature of deprived communities is the spatial concentration of social housing. Tenure-diversification in this context is not only about attracting higher-income groups into the area, but also about providing the opportunity for 'successful' local residents to remain in the area by offering greater choice of housing types and tenures (SG, 2007; see also McKee, In Press). Creating a better balance of housing tenures and incomes is pivotal not only in tackling concentrations of poverty and disadvantage, but also in realising government aspirations for more cohesive, sustainable communities (SG, 2007). Despite being a key government priority at both the UK and devolved levels, the evidence base for mixed-communities remains highly contested (Lupton and Fuller, 2009).

Post-devolution, increasing homeownership amongst low and middle income groups has emerged as an important strand of housing-led regeneration, with tools to encourage this including the sale of public housing, the inclusion of affordable housing in new private housing developments, and the growth of shared equity and shared ownership schemes, which now represent a small but increasingly important segment of the housing market (CCHPR, 2008; Newhaven, 2008; Newhaven Research and University of Glasgow, 2008; Bramley and Morgan, 1998; Bramley and Dunsmore, 1996; Bramley, et al, 2002, 2007; Munro, 2007; Wallace, 1998). In order to rebrand 
p. 40. Promoting Homeownership at the Margins: the experience of low-cost homeownership purchasers in regeneration areas

and simplify the complex array of low-cost homeownership initiatives on offer, the Secretary for Health and Well-Being, Nicola Sturgeon, announced in 2007 the Scottish Government's new Low-Cost Initiative for First-Time Buyers: known as LIFT (SG, 2007, 2008). It brings together a plethora of schemes designed to help people realise their aspirations for homeownership, with a particular emphasis on first-time-buyers, especially those currently in the rental sector or living with relatives. Two key elements include:

- shared equity: it effectively provides an interest free loan enabling purchasers to buy a majority share in their property (normally between 60 and 80 per cent), thereby making mortgage payments more affordable. Applicants are subject to an income-test and must take out the maximum equity they can afford. After two years households can increase their share up to 100 per cent. When the property is sold both the shared equity owner and the social landlord will receive their relative shares of the property value. Shared equity owners have sole responsibility for all repair and maintenance costs, including any communal charges. The scheme covers new-build and more recently, properties sold on the open market. It was previously branded Homestake

- shared ownership: is the older of the two schemes. Shared owners pay part mortgage and part rent in the form of an occupancy payment to their social landlord, with equity shares starting from 25 per cent. Purchasers have responsibility for repair and maintenance costs, although the landlord may maintain common parts and services in certain estates (especially flats). Eligibility is dependent on income.

Although not new, low-cost homeownership initiatives are likely to become an increasingly important feature of the UK housing market as affordability problems are exacerbated by the economic downturn. Post credit-crunch, mortgage availability is now much more constrained, with levels of repossessions also on the increase (SG, 2010). The new era of fiscal austerity and budget cuts announced by the UK coalition government has also put increasing pressure on social housing budgets, as housing is not a protected area of public spending in the same way that health and education are. Faced with imminent budget cuts and increasing demand for social housing, the notion of 'affordable housing' is now being reimagined. The recent Scottish Government (2010) paper Fresh Thinking, New Ideas suggests an increasingly marginal, welfare role for social housing in the future, with affordable housing being much more geared towards housing for sale through low-cost homeownership; not least because the cost to the public purse is considerably less. Whilst housing association grant subsidy for new build social housing has a target of $£ 75,000$, shared equity has a median government contribution of $£ 43,000$ (SG, 2009b).

Continuing to promote homeownership to low-income groups at a time when the economy is in difficulty is not however unproblematic, for these socio-economic groups are particularly vulnerable to labour and housing market volatility. Consequently, commentators have suggested that now is perhaps the time to requisition the privileged status accorded to homeownership in the UK, and for both the UK and Scottish governments to adopt more tenure-neutral policies, which would enable the rental sector to take on a greater social role during these difficult and austere times, for example through mid-market rent (Mclntyre and McKee, In Press; Newhaven Research and University of Glasgow, 2008). 
p. 41. Promoting Homeownership at the Margins: the experience of low-cost homeownership purchasers in regeneration areas

\section{Research design}

In order to gain deeper insight into purchasers' experiences of low-cost homeownership schemes, this paper draws on qualitative research from a small seedcorn-funded study conducted in west-central Scotland during June-September 2009. This region of Scotland was chosen because statistics highlight local authority areas have higher concentrations of poverty and lower levels of homeownership than the Scottish average. Median earnings in West Dunbartonshire and Glasgow City are 88 and 94 per cent of the Scottish average respectively; although average house prices in these local authority areas are lower than the national average, they both have large social rented sectors which comprise over 40 per cent of the tenure structure (www.sns.co.uk). These statistics reflect the legacy of de-industratialisation that still scars much of the Scottish landscape in the west, and the traditionally higher levels of social housing that are prevalent. Precisely because of this, tenure-mix through affordable housing for sale was an explicit feature of the Local Housing Strategies of the two local authorities under focus: Glasgow and West Dunbartonshire (GCC, 2005; WDC, 2004). It plays an important regeneration role in diversifying the tenure structure, thereby attracting and retaining more affluent households, which is important both for local economic development and the creation of sustainable communities.

The project involved 14 in-depth, face-to-face interviews with individuals who had purchased their home through either shared equity or shared ownership schemes. To anonymise respondents for confidentiality reasons, pseudonyms were used. Whilst the sample is small, it nonetheless offers a rich, in-depth understanding of the key issues: something less easy to achieve through the structured household surveys and telephone interviews traditionally favoured by researchers in this field (see for example, Bramley, et al., 2002; 2007). Individuals were drawn from three housing developments all located in deprived neighbourhoods that have undergone significant regeneration in recent years:

- Glasgow Greater Govan: established shared ownership scheme, which included new-build tenement flats built in the 1990s and older, rehabilitated pre-1919 housing. The local area has a high level of social housing compared to the city average

- Glasgow North East: a new-build shared equity scheme built on a peripheral social housing estate. These properties are small, semi-detached houses situated in a mixed-development that also includes social housing and private housing for sale

- Clydebank: a new-supply shared equity scheme of tenement flats built in a neighbourhood previously dominated by public sector housing.

Participants were drawn from a range of socio-economic backgrounds, including professional occupations such as the police and social work. However, over 40 per cent earned less than $£ 25,000$ per annum, and 20 per cent less than $£ 15,000$, with those at the lower end of the income scale tending to be shared owners. Participants also had quite different housing histories, with 14 per cent being new households, and over two-thirds previously residing in the rental sector (36 per cent of which were from the social rented sector). The next two sections of this paper draw on qualitative interviews in order to explore households' perceptions and experiences of these schemes. 
p. 42. Promoting Homeownership at the Margins: the experience of low-cost homeownership purchasers in regeneration areas

\section{Positive benefits and opportunities of low-cost homeownership schemes}

\section{Affordability}

Affordability was described by purchasers as the main benefit and attraction of these low-cost homeownership schemes, and indeed, this is one of the main policy objectives these initiatives were designed to meet. By buying a smaller stake in a property, purchasers can reduce their required deposit and monthly mortgage payments. Given the average deposit of a first-time-buyer in the UK is now 25 per cent of the property price (CML, 2009, cited in SG, 2010: 10), being able to reduce overall borrowings represents an important financial saving in this difficult economic climate in which lending is highly restricted. This is particularly important for single households who may lack the income multiples (and necessary deposit) to purchase a property on the open market through conventional mortgage products. Moreover, the flexibility of such schemes means households can potentially increase (or decrease) their 'share' to suit their life circumstances, for example when they have a young family, or when their earnings change:

"Because I am single there are only so many options open to me [...]. It's really, really hard to get a mortgage nowadays, the majority of mortgage companies are looking for crazy deposits maybe up to thirty per cent which just wasn't feasible for a single person to buy a house. So shared equity seemed the more logical approach to get on the ladder."

(Natalie, 18-25 years old, shared equity purchaser, Glasgow North East, new household)

As the size of a shared ownership/equity mortgage is generally less than conventional homeownership this should also translate into less exposure to the risks of high mortgage borrowing (Bramley and Dunmore, 1996). The risks associated with negative equity are also shared between the purchaser and the developer, for when the property is sold each party receives their respective share of the property's value, which may go down as well as up. This is important in a regeneration context where the properties are potentially lower value and house price gains less assured.

\section{Quality}

It was not simply the cost that made these schemes attractive. Households described how low-cost homeownership products enabled them to buy a 'better quality home' than they would otherwise have been able to afford on the open market. In particular, such schemes broadened their available options by allowing them to enter the newbuild sector, as opposed to having to restrict their purchasing options to the older, cheaper, ex-council properties that would have been in their price range. This is significant in a regeneration context as it widens the choice of house types on offer to first-time-buyers, thus increasing the likelihood of aspiring homeowners remaining locally:

Interviewer: "You were talking about when you first started looking at houses in the local market. How easy was it for you to buy in the market?"

Angela: "A lot of them were affordable, but it wasn't what I was desiring at all in quality. This has given me a better opportunity to get on to the property ladder."

(Angela, 36-45 years old, shared equity purchaser, Clydebank, previously in social housing) 
p. 43. Promoting Homeownership at the Margins: the experience of low-cost homeownership purchasers in regeneration areas

Buying a new build property was also perceived to reduce maintenance costs, and avoid the need to renovate or decorate the property at the point of purchase. This was important for those at the lower end of the income scale who did not have reserves of savings to draw on. Nonetheless, households who purchased a new-build property commented on the difficulties in getting the developer to attend to 'snagging' issues. In one particular development, which had originally been intended to be houses for sale but had been sold to a housing association because of the credit-crunch, households were frustrated with the overall poor quality and finish of their properties. Although perhaps an atypical case, it does raise the question of whether it is appropriate for the social rented sector to bail out private developers by purchasing properties difficult to sell on the open market, especially if they are lower quality than what public sector standards would normally dictate.

\section{Local connection}

Low-cost homeownership schemes within regeneration areas enable 'successful' households located in the rental sector to remain in the local area, where they already have established social networks, instead of having to move away in search of more suitable properties elsewhere. Indeed, all but one of the interviewees had purchased their property in the geographical area in which they grew up. They liked the familiarity and security this local connection gave them, as well as being close to their friends and family. Retired households in particular expressed that it was more difficult to meet new people later in life, and therefore that they were more dependent on longstanding area based networks. These local networks were important sources of informal care, especially for those who relied on family to help them maintain their independence in their home.

\section{Housing need}

Finally, as shared equity and shared ownership schemes in Scotland are specifically targeted at helping those in the rental sector become homeowners, they also free-up social housing for those in greater need (Bramley, et al., 2007). Although the sample size of this study was small, it would seem to validate this argument, for 5 of the 14 participants entered low-cost homeownership from the social rented sector. Nonetheless, there does seem to be a policy tension between promoting sustainable, mixed communities on the one hand, whilst at the same time encouraging working households to exit the social rented sector, thus increasing social polarisation between homeowners and social renters (see McKee, In Press).

\section{The challenges and problems associated with low-cost homeownership Schemes}

\section{Financial costs of homeownership}

The majority of households were first-time-buyers and had previously been in the rental sector or living with relatives. For those coming from the social rented sector in particular, taking out a mortgage in order to purchase a property was a source of much stress and anxiety. Individuals were concerned about over-stretching themselves, and what would happen if their financial situation took a turn for the worse, for example due to unemployment: 
p. 44. Promoting Homeownership at the Margins: the experience of low-cost homeownership purchasers in regeneration areas

"Well I think [a mortgage] is a noose round your neck, it is definitely a worry. You know you've got to make sure you keep your job and that."

(Eleanor, 46-55 years old, shared owner, Glasgow Greater Govan, previously in social housing)

"Mortgage wise and things like that it's a big commitment, and you have to be able to do your sums."

(Angela, 36-45 years old, shared equity purchaser, Clydebank, previously in social housing)

Individuals were not only concerned about how the recession might impact upon them personally, but also how they would reconcile their household budgets now that their housing costs had increased (as in most instances mortgage payments were higher than previous social rents), especially now they could no longer rely on housing benefit as their safety-net. Whilst shared owners can receive housing benefit to cover the 'occupancy payment' they make to their social landlord they cannot receive it for the mortgaged part of the property (neither can shared equity purchasers). This is significant because it may inhibit the household's ability to manage the risk of entering and sustaining low-paid and insecure employment. By contrast, research in England has highlighted the positive in-work benefits of residing in social housing (Fletcher et al., 2008).

For those purchasers coming from the private rented sector, or who had previously been homeowners, the financial costs of homeownership were less of an issue, with this group largely accepting their mortgage as 'something everyone has'. Interestingly, some of the older shared-owners had no mortgage at all because they had since paid it off. They only had an occupancy payment to make to their social landlord, which in many cases was cheaper than typical non-market rents. Housing costs for this group were therefore substantially less as compared to when they were in the rental sector. This highlights the importance of not treating low-cost homeowners as a homogenous group, whilst also illustrating the particular vulnerabilities of those entering homeownership from the social rented sector.

In addition to making mortgage payments, the additional costs of insurance products, and the financial responsibility of maintaining and repairing the property were important. This was particularly true of those who did not have such costs when in the rental sector or living with relatives, and was more acutely experienced by those living in older properties in which the age of the dwelling necessitated some degree of upgrading and modernisation. This underlines how the cost of homeownership goes beyond the monthly mortgage payment. Yet for lower income groups being able to meet these financial outlays can be a challenge. This raises the question of whether such households would be better placed in the rental sector, where the landlord would have responsibility for repair issues and buildings insurance.

\section{Limited financial products}

The interviews also highlight the difficulty in securing a mortgage for a shared equity/ownership property, because of the limited range of lenders who would fund this type of purchase. The effect of this was not only a reduction in choice for consumers, but ultimately less competitive mortgage products with higher interest rates - a finding reiterated by research in England (CCHPR, 2008). Given that these schemes are being targeted at lower income groups, many of which are coming from social housing, the more expensive nature of their borrowing has significant social justice implications: 
p. 45. Promoting Homeownership at the Margins: the experience of low-cost homeownership purchasers in regeneration areas

"There's only a few (lenders). You can't go the whole market. And the APR is higher, than what it would normally be. Which isn't fair either."

(Ina, 46-55 years old, shared equity purchaser, Clydebank, previously a homeowner)

Moreover, all interviewees reiterated that they would have liked some impartial financial advice, although they respected it was not necessarily the housing association's role to provide this. Several individuals expressed frustration that when they had visited their lender or a mortgage adviser they were not familiar with the specifics of how these low-cost homeownership schemes operated, and consequently, were not perceived to offer very 'competitive' deals:

"We were phoning up [our bank] and they hadn't a clue what we were talking about. They were quite stroppy with us. They couldn't understand why we didn't want a full mortgage. They didn't have a clue. And it was through the Internet that we found anything [...] And we found out that Edinburgh had done a fair bit of shared equity. They were more advanced than Glasgow. So we phoned up a financial advisor there, and he sent through some information anyway, on different banks."

(Kerry, 46-55 years old, shared equity purchaser, Glasgow North East, previously in social housing)

\section{Staircasing}

The flexibility of these schemes in terms of being able to increase the stake owned at a future date was popular, for it enabled households to alter their housing costs to suit their life circumstances. Nonetheless, for a household to increase their share, they need to have the property re-valued and re-mortgage their home. Ultimately there are transactions costs associated with doing so in terms of legal and financial fees. The cost of additional borrowing is also dependent on fluctuating house prices and variable interest rates.

There are also notable differences between the two schemes. Shared owners generally have smaller stakes in their property, as low as 25 per cent, which makes it more difficult for them to ever become full owners. Moreover, their on average lower income, and the fact they have to pay an occupancy payment in addition to a mortgage payment, also makes it financially more untenable for them to bridge the equity gap. This is reflected in the discussion with Frank, a shared owner in the Glasgow Greater Govan area who described how he felt 'trapped' because full homeownership was financially beyond his reach:

"You'd need to take out another mortgage to get another percentage off [the association]. And I feel that all you're doing is giving the association a loan again because all they're going to do is take rent off you again [...] It's never going to be yours. And people buy a house so that it's theirs. You struggle to pay it but at the end of the day that's going to be mine. But this will never be mine. I'll struggle. This will put me in my grave trying to keep a roof over my head. And it will never be mine."

(Frank, 46-55 years old, shared owner, Glasgow Greater Govan, previously a homeowner). 
p. 46. Promoting Homeownership at the Margins: the experience of low-cost homeownership purchasers in regeneration areas

The situation for shared equity purchasers is slightly different. Given they generally own larger shares in their property to begin with, remortgaging to fund the purchase of the full property is more attainable for them, as there is a smaller gap to close in terms of reaching 'full' ownership. Nonetheless, given the household types that tend to be concentrated in low-cost homeownership schemes, borrowing to fund staircasing up is far from a simple formality. This is reflected in the case of Nathalie. She purchased 75 per cent of a new-build shared equity property, but in order to become a 'full' owner she would need to borrow a further $£ 26,000$ in the future. As a single person, already at the margins of housing affordability she lamented that the likelihood of being able to do so was unlikely.

This raises the important question of whether it is appropriate that governments sell people the 'dream' of homeownership, when financially for many of these low-income groups it is not within their reach. If households are not able to make the transition into 'full' homeownership then there is a danger that it may become an intermediate tenure that people cannot move out of, and therefore become trapped in (Wallace, 2008). This situation mirrors the ambiguous position of long leaseholder flats in England and Wales where purchasers have also chased the 'dream' of home ownership only to be burdened with financial pressures and feelings of being 'trapped' in their accommodation (Cole and Robinson, 2010).

\section{Administration of the scheme}

Scottish Government guidance states that housing associations should make applicants aware of the financial responsibilities attached to homeownership, as well as the specific costs and restrictions associated with low-cost homeownership schemes (SG, 2009a). However, nearly all of the participants in this study expressed the view that the fine details of the scheme were never really explained to them, and that they would have valued some information provided independent of the housing association. In particular, purchasers described their frustration at the lack of detailed guidance about how the schemes operated, especially the implications for them should they wish to sell their property or transfer it to a family member:

"I actually still don't know how it works. I know that I can't sell this house, unless I go to them and say I want to sell this house. Then they have to vet whoever wants to buy it. If I die, my sons or that can't move in. It's to get sold. I mean it's my house."

(Jane, 56-65 years, shared equity purchaser, Glasgow North East, formerly a homeowner)

Unlike conventional homeownership, restrictions apply in terms of who the property can pass on to following the owner's death. Government guidelines indicate that if the property does not pass to a spouse then it should be sold and the grant repaid, with any remaining profit transferring to the deceased's estate (SG, 2009a). The implication of this is that the property cannot be passed on to other relatives. Purchasers are also prohibited from renting out the property to a third party, limited in terms of what property size they can apply for (two-bed spaces more than their household size), and may even be prevented from increasing their stake in some geographical areas which have 'pressured area' status (SG, 2009a). Despite low-cost homeownership schemes being designed to encourage individuals to become 'responsible' homeowners who can enterprise their own lives, it would seem they are administered in a rather bureaucratic fashion, and may be more restrictive than a traditional social rented tenancy. This would seem to challenge many of the presumed 
p. 47. Promoting Homeownership at the Margins: the experience of low-cost homeownership purchasers in regeneration areas

benefits of homeownership such as autonomy, freedom and control (see for example Saunders, 1990).

The division of responsibilities between landlord and purchasers was a further issue, and point of contention, specifically in relation to responsibility for repairs and maintenance. This parallels leaseholder debates in England and Wales (Cole and Robinson, 2010). It is a particular issue for shared ownership, for whilst these households are given responsibility for repairs and maintenance they still have to pay an occupancy payment to their landlord. This in turn creates confusion over who is actually 'responsible' for the upkeep of the property, which purchasers expecting developers to fulfil a 'traditional' landlord role. The recent push towards shared equity was designed to alleviate this problem because it is more like conventional homeownership. Evidence from this study suggests however that confusion still remains, as several purchasers (from across the two schemes) commented that they had been under the impression the social landlord was responsible for maintaining the property.

\section{Conclusion}

Low-cost homeownership products have been integral to diversifying the tenure structure at the neighbourhood level in Scotland. Not only do such schemes attract more affluent households into regeneration areas, but by increasing the choice of house types and tenures on offer they may also encourage 'successful' households to remain in the local neighbourhood. Both objectives are important to realising Scottish Government priorities around sustainable communities and social inclusion.

As the empirical data highlights, low-cost homeownership products pose a number of challenges for purchasers, in addition to any positive benefits and opportunities that might be experienced. The financial costs of homeownership, as well as the additional expenditure associated with insurance, and repairs and maintenance can be a financial stretch to low-income groups, especially those who had previously resided in the rental sector. Moreover, the limited range of financial products on offer means purchasers may pay a higher premium for the borrowing, whilst facing restrictions on the use and re-sale of their property as compared to 'normal' homeowners. The ability to staircase up their share and become 'full' homeowners in the traditional sense is also questionable.

Given increasing concerns about the sustainability of homeownership for lowincome groups this raises the important public policy question of whether it is appropriate for government to be promoting such schemes in the first place. Whilst they undoubtedly help realise the policy objective of increasing owner-occupation, they are not without risk. Perhaps government should take advantage of these difficult economic times and rethink its attitude to tenure. Improving the quality and variety of the rental sector might be a preferable alternative to providing affordable housing for sale. Whilst there is inevitably a public cost to such a policy, it may nonetheless create a more well-functioning housing system in the long run.

\section{Acknowledgements}

This study was funded by the Urban Studies Foundation. Thanks are owed to all the individuals who participated in the interviews and to contacts within the local authorities and housing associations. 
p. 48. Promoting Homeownership at the Margins: the experience of low-cost homeownership purchasers in regeneration areas

* Correspondence Address: Kim McKee, Centre for Housing Research, The Observatory, Buchanan Gardens, University of St Andrews, St Andrews, Fife KY16 9LZ. E-mail: km410@st-andrews.ac.uk

\section{Reference List}

Bramley, G. and Dunmore, K. (1996) Shared Ownership: short-term expedient or longterm major tenure. Housing Studies 11, 1, 105-131.

Bramley, G. and Morgan, J. (1998) Low Cost Home Ownership Initiatives in the UK. Housing Studies, 13, 4, 567-586.

Bramley, G. Morgan, J. Cousins, L. and Dunmore, K. (2002) Evaluation of the Low-Cost Homeownership Programme. Housing Research Summary. London: ODPM.

Bramley, G., Morgan, J. and Littlewood, M. (2007) Initial Evaluation of the Open Market Homestake Pilot. Research from Communities Scotland: research report 87. Edinburgh: Communities Scotland.

Cole, I. and Robinson, D. (2010) Owners Yet Tenants: the position of leaseholders in flats in England and Wales. Housing Studies 15, 4, 595-612.

CCHPR (2008) Low Cost Homeownership: affordability, risks and issues. Cambridge: Cambridge Centre for Housing and Planning Research.

CLG (2007) Social Mobility and Homeownership: a risk assessment. London: Communities and Local Government.

Fletcher, D., Gore, T., Reeve, K. and Robinson, D. (2008) Social Housing and Worklessness: qualitative research findings. Research Report No. 521. London: Department for Work and Pensions.

Glasgow City Council (2005) Glasgow's Local Housing Strategy 2003-2008: 2005 update. Glasgow: Glasgow City Council.

Gurney, C. (1999a) Pride and Prejudice: discourses of normalisation in public and private accounts of home ownership. Housing Studies 14, 2, 163-183.

Lupton, R. and Fuller, C. (2009) Mixed Communities: a new approach to spatially concentrated poverty in England. International Journal of Urban and Regional Research 33, 4, 1014-1028.

McKee, K. (In Press) The End of the Right to Buy and the Future of Social Housing in Scotland. Local Economy.

Mclntyre, Z. and McKee, K. (In Press) Creating Sustainable Communities through Tenure-mix: the responsibilisation of marginal homeowners in Scotland, Geojournal.

Munro, M. (2007) Evaluating Policy towards Increasing Owner Occupation. Housing Studies 22, 2, 243-260.

Newhaven Research (2008) All Pain, No Gain? Finding the Balance. Edinburgh: ClH Scotland.

Newhaven Research and University of Glasgow (2008) The Credit Crunch and the Scottish Housing System. ClH Scotland: Edinburgh.

Saunders, P. (1990) A Nation of Home Owners. London: Unwin Hyman.

SG (2007) Firm Foundations: the future of housing in Scotland. Edinburgh: Scottish Government.

SG (2008) First Time Buyers, retrieved 31/1/10: http://www.scotland.gov.uk/Topics/ Built-environment/Housing/BuyingSelling/lift

SG (2009a) New Supply Shared Equity Scheme: Administrative Procedures. Retrieved 15/11/09: http://www.scotland.gov.uk/Resource/Doc/277970/0083509.pdf

SG (2009b) Low Cost Homeownership. Personal email communication, 2 ${ }^{\text {nd }}$ December 2009.

SG (2010) Housing: fresh thinking, new ideas. Edinburgh: Scottish Government. 
p. 49. Promoting Homeownership at the Margins: the experience of low-cost homeownership purchasers in regeneration areas

Stephens, M, Ford, J; Spencer, P, Wallace, A, Wilcox, S. and Williams, P. (2008) Housing Market Recessions and Affordable Home Ownership. York: JRF.

Tunstall, R. (2003) Mixed Tenure' Policy in the UK: privatisation, pluralism or euphemism? Housing, Theory and Society 20, 3, 153-159.

Wallace, A. (2008) Achieving Mobility in the Intermediate Housing Market: moving up and moving on? York and Coventry: JRF and $\mathrm{ClH}$.

West Dunbartonshire Council (2004) West Dunbartonshire Local Housing Strategy 2004-2009. West Dunbartonshire Council. 